\title{
Expression of Cyanobacterial Genes Involved in Heterocyst Differentiation and Dinitrogen Fixation Along a Plant Symbiosis Development Profile
}

\author{
Chun-Mei Wang, ${ }^{1}$ Martin Ekman, ${ }^{2}$ and Birgitta Bergman ${ }^{2}$ \\ ${ }^{1}$ Department of Biological Pharmaceutics, School of Chinese Pharmacy, Beijing University of Chinese Medicine, \\ 100029 Beijing, China; ${ }^{2}$ Department of Botany, Stockholm University, SE-106 91 Stockholm, Sweden
}

Submitted 26 June 2003. Accepted 4 November 2003.

\begin{abstract}
Members of the cyanobiont genus Nostoc, forming an endosymbiosis with members of the angiosperm genus Gunnera, undergo a number of characteristic phenotypic changes during the development of the symbiosis, the genetic background of which is largely unknown. Transcription patterns of genes related to heterocyst differentiation and dinitrogen fixation and corresponding protein profiles were examined, using reverse transcription-polymerase chain reaction and Western blots, along a developmental (apex to mature parts) sequence in Gunnera magellanica and $G$. manicata and under mimicked symbiotic conditions in a free-living Gunnera isolate (Nostoc strain 0102). The hetR gene was highly expressed and correlated positively with an increase in heterocyst frequency and with ntcA expression, whereas nifH expression was already high close to the growing apex and $g \ln B\left(\mathrm{P}_{\mathrm{II}}\right)$ expression decreased along the symbiotic profile. Although gene expression appeared to be regulated to a large extent in the same fashion as in free-living cyanobacteria, significant differences were apparent, such as the overexpression of both hetR and $n t c A$ and the contrasting downregulation of $g \ln B$, features indicating important regulatory differences between symbiotic and free-living cyanobacteria. The significance of these findings is discussed in a symbiotic context.
\end{abstract}

It now seems beyond doubt that cyanobacteria, at some initial stage during evolution, entered one or more ancestral eukaryotic cells or organisms (Martin et al. 2002; Schopf 2000). Subsequently, these became fully integrated but genetically rudimentized into photosynthetic organelles, chloroplasts. A similar behavior is apparent in a few extant cyanobacteria, those capable of symbiotic interactions with eukaryotes ranging from algae to angiosperms (Rai et al. 2000). Among these, the cyanobacterial-Gunnera symbiosis is exclusive and of great evolutionary significance, being the only one that involves an angiosperm and an intracellular containment of cyanobacteria (Bergman 2002; Bergman et al. 1992a), and this symbiosis may therefore function as a model system for understanding mechanisms involved in symbiosis and in chloroplast evolution.

The cyanobionts (cyanobacteria in symbiosis) in Gunnera spp. belong to the dinitrogen-fixing heterocystous genus Nostoc (Nilsson et al. 2000; Rasmussen and Svenning 2001).

Corresponding author: Birgitta Bergman; E-mail: bergmanb@botan.su.se; Telephone: +468 163751; Fax: +468165525.
Nostoc spp. enter through stem glands and become restricted to certain Gunnera cells intermixed with noninfected cells. New cell infections continuously take place at the growing stem apex, and the resulting symbiotic tissues occur as small blue-green patches along the rhizomatous stems or, as in some smaller Gunnera species, along their stolons (Bergman 2002).

Typical for cyanobacteria in plant symbioses is the elicitation of cell differentiation events leading to morphological changes and metabolic adaptations, some of which go far beyond those seen under any free-living conditions. For instance, on contact with the Gunnera plant, cyanobacteria differentiate into the motile hormogonium stage, but on entering the host cells, a redifferentiation into vegetative filaments with a radically increased heterocyst frequency ( 70 to $80 \%$ ) takes place, accompanied by altered heterocyst spacing patterns (Bergman 2002; Bergman et al. 1992b, 1996). The heterocysts act as nitrogen-producing entities capable of supporting the entire symbiosis with combined nitrogen, since up to $90 \%$ of the dinitrogen fixed is exported from the cyanobacterium (Silvester et al. 1996). In return, the host plant supplies the cyanobiont with fixed carbon via photosynthesis (Black et al. 2002; Söderbäck and Bergman 1993) and possibly all other nutrients required.

The morphological and physiological changes observed in Nostoc strains in the Gunnera cells are therefore, to a large extent, related to uptake and metabolism of nitrogen. In freeliving cyanobacteria, the physiological response to different nitrogen regimes is regulated by the NtcA protein, which belongs to a family of bacterial regulatory proteins typified by the cyclic AMP receptor protein, Crp. NtcA regulates the expression of certain genes involved in nitrogen assimilation (Herrero et al. 2001) and also autoregulates its own expression (Luque et al. 1994; Ramasubramanian et al. 1996). NtcA senses the nitrogen status via 2-oxoglutarate, and hence, the intracellular carbon to nitrogen $(\mathrm{C}: \mathrm{N})$ balance is of importance (Muro-Pastor et al. 2001; Tanigawa et al. 2002; Vazquez-Bermudez et al. 2002). NtcA is also required for initiation of heterocyst differentiation (Adams and Duggan 1999; Frias et al. 1994).

In unicellular cyanobacteria, the signal transduction protein $\mathrm{P}_{\mathrm{II}}$ (encoded by $g \ln B$ ) acts as a sensor of the cellular nitrogen and carbon status. The $\mathrm{P}_{\mathrm{II}}$ protein is phosphorylated to different degrees, depending on the carbon and nitrogen supply (Irmler et al. 1997). glnB expression in Synechococcus sp. strain PCC 7942 is regulated by NtcA (Lee et al. 1999). The function of $\mathrm{P}_{\mathrm{II}}$ in filamentous cyanobacteria has been less studied, and data suggest that its regulation may be different (Hanson et al. 1998). 
$h e t R$ is the master gene for differentiation of heterocysts and resting spores (akinetes) in Anabaena and Nostoc spp. (Buikema and Haselkorn 1991, 2001; Leganes et al. 1994). HetR acts as a serine-type protease (Zhou et al. 1998a), and transcription of hetR is indirectly controlled by NtcA (Zhou et al. 1998b). A late event in the development of heterocysts is expression of nitrogenase, the dinitrogen-fixing enzyme complex. This is composed of two proteins, dinitrogenase reductase, encoded by nifH, and dinitrogenase, encoded by nifKD. NtcA may also indirectly control the expression of the nif genes (Frias et al. 1994).

In spite of all the dramatic phenotypic and metabolic adaptations taking place in cyanobacteria entering cells of Gunnera spp., the molecular background is largely unknown. In order to decipher regulatory cascades in planta, the expression of the cyanobacterial $n t c A, g \ln B$, hetR, and $n i f H$ genes was studied along developmental plant gradients and in a free-living isolate exposed to mimicked symbiotic conditions (varying $\mathrm{C}: \mathrm{N}$ ratios and light).

\section{RESULTS}

\section{Heterocyst development.}

Two cyanobacteria-infected Gunnera species differing in their macro morphology were examined: the large $G$. manicata (up to $2 \mathrm{~m}$ in height) with thick stems and rhizomes and the considerably smaller and stoloniferous $G$. magellanica (up to $10 \mathrm{~cm}$ in height). The cyanobacteria-infected symbiotic tissues differed considerably in size between the Gunnera species, ranging from 2 to $15 \mathrm{~mm}$ in diameter in the stem of $G$. manicata and 0.2 to $5 \mathrm{~mm}$ along the stolons of $G$. magellanica.

Plant tissues infected with cyanobacteria were dissected from eight different Gunnera stages, from the very newly infected tissues at the growing plant apex to the older, more mature parts. As similar results were obtained for the cyanobionts located along the plant age gradients in both plant species, only results from the $G$. magellanica symbiosis are presented here.
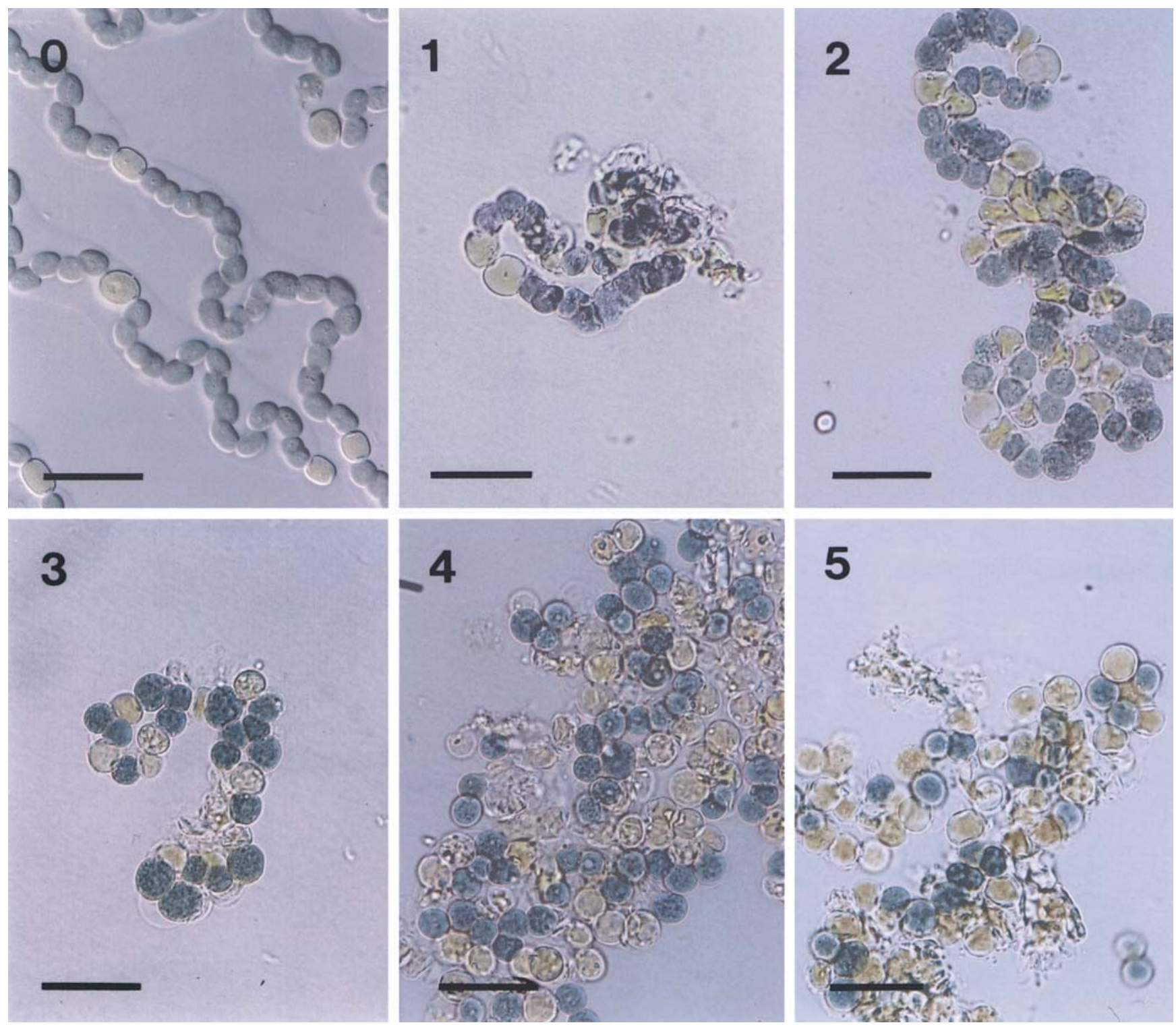

Fig. 1. Development patterns in frequency of heterocysts in Nostoc colonies along the stem of a Gunnera magellanica plantlet. The heterocysts are recognized as the larger and more transparent cell type, while the vegetative cells are darker pigmented. 0, Nostoc isolated from G. magellanica and grown as a free-living isolate in the absence of combined nitrogen (BG11 $)$, 95\% heterocysts; $\mathbf{1}$, Nostoc colonies freshly isolated from recently infected Gunnera glands located close to the plant stem apex ( 3 to $4 \mathrm{~mm}$ ), 10 to $20 \%$ heterocysts; 2, Nostoc isolated from glands about 5 to $6 \mathrm{~mm}$ from the apex, 20 to $30 \%$ heterocysts; $\mathbf{3}, 7$ to $8 \mathrm{~mm}, 30$ to $40 \%$; 4,9 to $10 \mathrm{~mm}, 40$ to $50 \%$; and $\mathbf{5}, 11$ to $12 \mathrm{~mm}$ from the apex, 50 to $60 \%$ heterocysts. Bars indicate $20 \mu \mathrm{m}$. 
As seen in Figure 1, the heterocyst frequency of the free-living Nostoc strain 0102, isolated from stolons of G. magellanica two weeks earlier, was about $5 \%$ when grown in the absence of combined nitrogen (control, stage 0). Small cyanobacterial inocula were apparent in the symbiotic tissues dissected from the very young growing Gunnera apexes. At this stage (data not shown), most cyanobacterial filaments were composed of photosynthetic vegetative cells, possibly recently developed from hormogonia. Intermediate aged infected Gunnera cells about 3 to $4 \mathrm{~mm}$ from the apex contained an increasing number of cyanobacterial filaments with an increasing heterocyst frequency, already reaching about 10 to $20 \%$ at stage 1 (Fig. 1). Further down the stem 5 to $6 \mathrm{~mm}$ from the apex, the symbiotic plant cells were more or less filled with
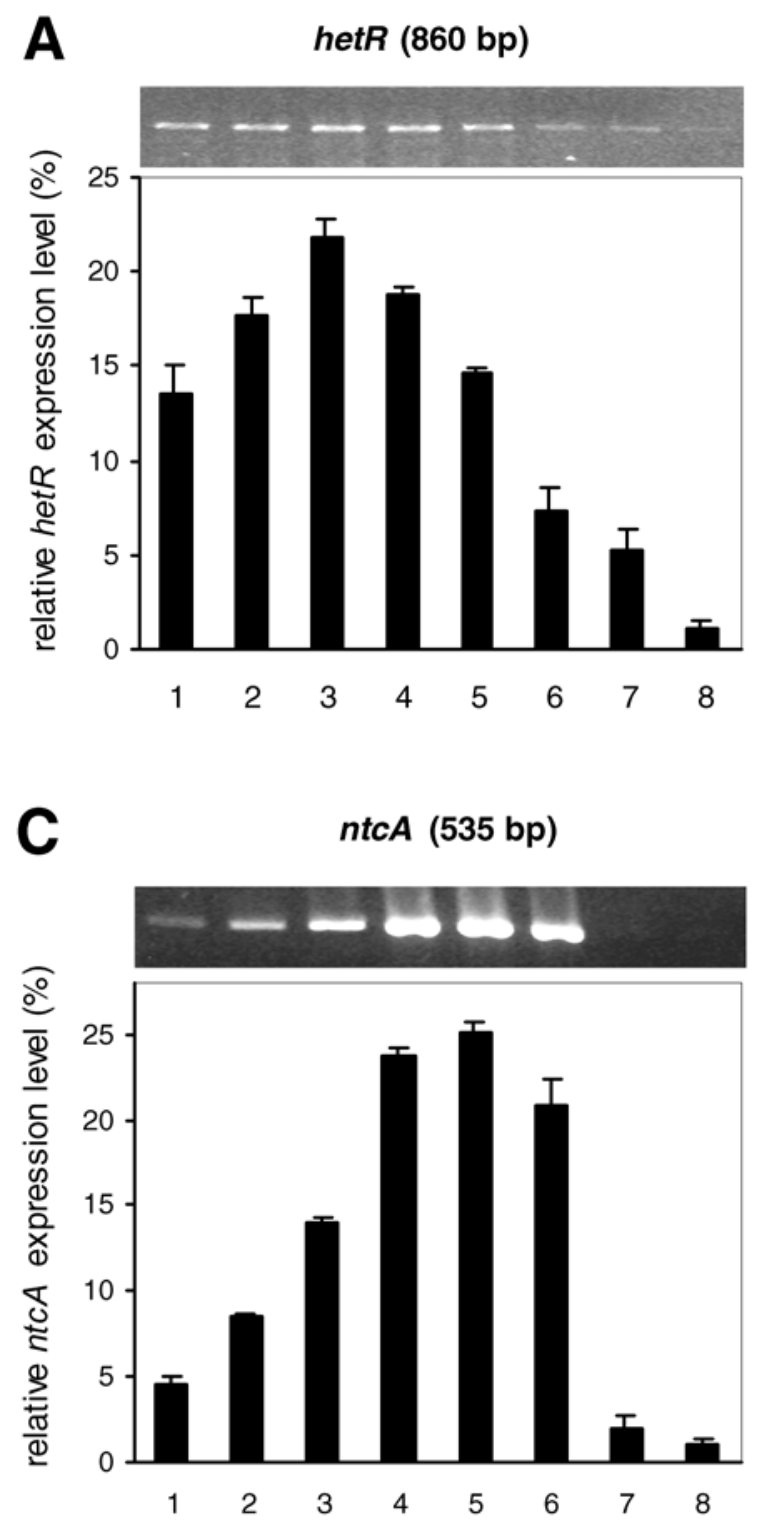

cyanobacteria with a heterocyst frequency reaching about 20 to $30 \%$ (stage 2). The cyanobacterial biomass then increased further, and a heterocyst frequency up to 50 to $60 \%$ was apparent 11 to $12 \mathrm{~mm}$ from the apex (stage 5). Subsequent estimates of heterocyst frequencies were difficult, due to the high number of degenerate cells at these stages (stage 6, 7, and 8; data not shown).

\section{Developmental patterns}

of gene expression and protein levels.

In order to characterize the expression of four cyanobacterial genes connected to signaling $(n t c A$ and $g \ln B)$, heterocyst differentiation (hetR), and dinitrogen fixation (nifH), mRNA was isolated, and expression patterns were analyzed (using a
B nifH (690 bp)

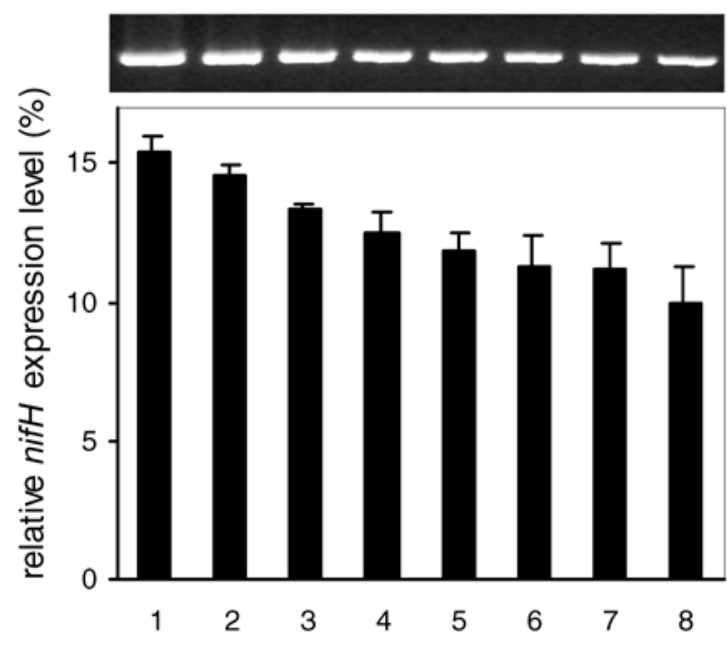

D

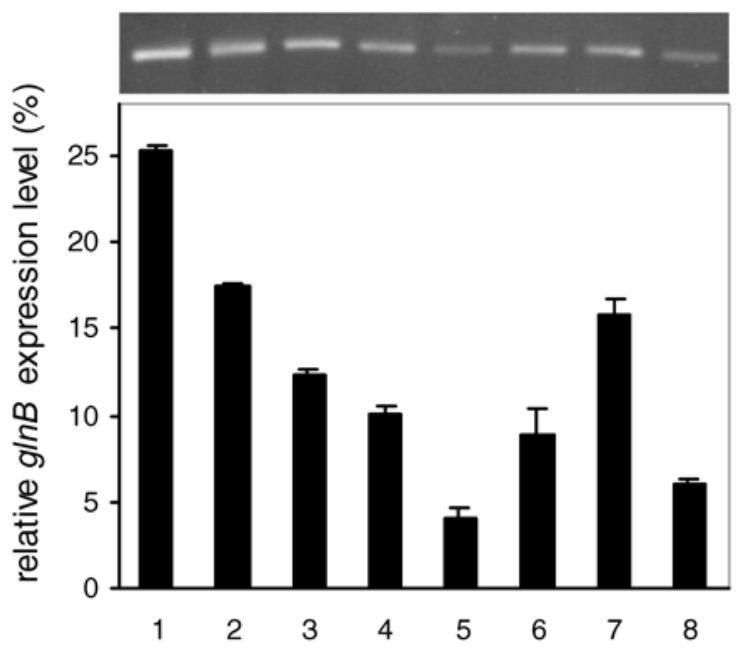

16S rRNA (514 bp)

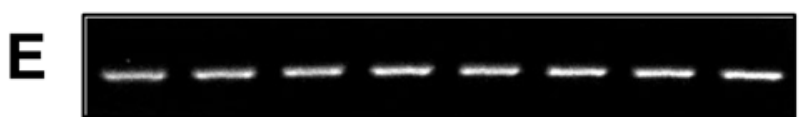

Fig. 2. Developmental patterns in Nostoc gene expression along the stem of a Gunnera magellanica plantlet. Agarose gels show the transcripts obtained using reverse transcription-polymerase chain reaction for the indicated genes. Histograms show the corresponding relative expression levels of each of the four genes. The total expression level of eight stages was set as 100\%. 16S rRNA was included as a control for equal DNA loading. Cells were isolated from different infection sites along the stolon. All mRNA samples received a DNase treatment. Values are the mean \pm standard error $(n=3)$. 
one-step reverse transcription-polymerase chain reaction [RTPCR] method) in cyanobionts located in eight different positions along the Gunnera stems (corresponding to developmental stages 1 through 8 described above). Western blot assays were concomitantly carried out, to obtain protein level profiles for the corresponding gene products (except for HetR) along the same developmental profile. Cyanobacteria isolated from the differently sized $G$. magellanica and $G$. manicata were examined and compared. For comparative purposes, the expression of the same genes and proteins was examined in the free-living Nostoc strain 0102, recently isolated from $G$. magellanica.

The levels of expression of hetR in Nostoc isolates along the Gunnera stem varied significantly (Fig. 2A). In cyanobionts at the apex (stage 1) with a low heterocyst frequency (as compared with Figure 1), the hetR transcription activity was low. Before reaching the middle part of the developmental profile, the hetR transcription activity increased to a maximum (stage 3 ). At this stage, a heterocyst frequency of about 30 to $40 \%$ was recorded. het $R$ expression then declined continuously and was negligible in the oldest tissue (stage 8).

Already at the stem apex (stage 1), nifH transcription activity was at maximum (Fig. 2B). The activity then slowly declined towards older parts of the Gunnera stem. The NifH protein profile (Fig. 3A) differed to some extent from the nifH transcript pattern (Fig. 2B). The protein level increased to about stage 3, and then, it gradually declined towards older parts of the stem.

A low $n t c A$ expression level was observed in cyanobionts dissected from the very young growing plant apex. This was followed by a rapid increase in expression to a maximum about $10 \mathrm{~mm}$ from the G. magellanica apex (Fig. 2C, stage 4 through 6). Expression then rapidly declined towards older parts of the stem. The protein profile of NtcA correlated positively with the $n t c A$ expression pattern (Fig. 3B).

The $g \ln B$ expression was already high at the Gunnera apex and gradually declined, reaching a minimum at stage 5 (Fig. 2D). Expression of $g \ln B$ then increased again to stage 7 but then decreased once more in the oldest part of the profile. The $\mathrm{P}_{\mathrm{II}}$ protein profile (Fig. 3C) was similar to the $g \ln B$ transcription profile, reaching a minimum at stage 6 .

Effects of fructose and MSX (L-methionine-D,L-sulfoximine) on gene expression in Nostoc strain 0102.

The upregulation of $n t c A$, hetR, and nifH expression after removal of combined nitrogen is well documented for free-living heterocystous cyanobacteria. However, there are few studies on upregulations beyond the expression levels found under dinitrogen-fixing conditions, which appears to be the situation in symbiosis (discussed below). There are, in addition, few studies reporting effects of added sugars on expression of these genes, although heterotrophy persists in symbiosis. In an attempt to explain the symbiotic expression profiles detected, effects of a combination of the addition of fructose and nitrogen starvation on $n t c A$, hetR, nifH, and $g \ln B$ expression in light-grown cultures and the effect of darkness on expression of $g \ln B$ was examined in Nostoc strain 0102.

In general, transcription levels for all four genes were higher in the free-living isolate Nostoc strain 0102 compared with those in the freshly isolated cyanobionts from the Gunnera tissues. This may be explained by the considerably slower growth rate of the symbiotic (heterotrophic) cyanobionts (Rai et al. 2000), and direct comparisons of absolute expression levels in symbiotic and free-living cyanobacteria are therefore difficult.

Addition of $5 \mathrm{mM}$ fructose enhanced expression of hetR, nifH, and $n t c A$ in Nostoc strain 0102, while no significant changes in $g \ln B$ expression were observed (Fig. 4A). hetR ex-
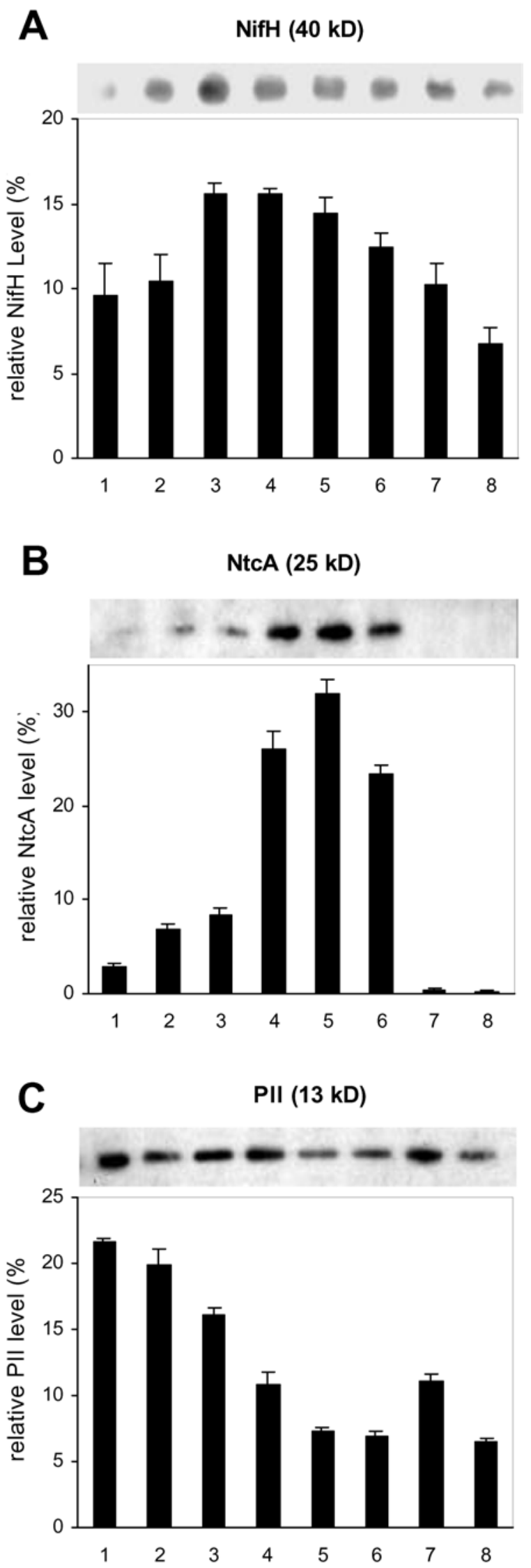

Fig. 3. Immunoblot analysis of the protein (NifH, NtcA, $\mathrm{P}_{\mathrm{II}}$ ) patterns in Nostoc isolates along the stem of a Gunnera magellanica plantlet. Histograms show the quantitative occurrence of the protein levels. The sum of the protein levels of eight stages was set as $100 \%$. Cells were isolated from different glands. Values are the mean \pm standard error $(n=3)$. 
pression peaked after $6 \mathrm{~h}$ and nifH expression after about $24 \mathrm{~h}$. $n t c A$ expression appeared to peak somewhat later than hetR, but there was no significant difference between the 6-h and the 24-h levels.

MSX, an analogue of $\mathrm{NH}_{4}^{+}$that inhibits glutamine synthetase activity, prevents primary ammonia assimilation in cyanobacteria (Stewart and Rowell 1975; Rogerson 1979). Addition of MSX was used as a means to reduce the available nitrogen levels, i.e., to mimic the predicted nitrogen starvation conditions experienced by cyanobacteria in symbiosis. Addition of $30 \mathrm{mM}$ MSX resulted in a significant increase in $n t c A$ expression. het $R$ expression increased in some cultures, but the average level did not differ from that of the control. The effect of MSX on nifH and $g \ln B$ expression varied between experiments with significant effects observed (Fig. 4B).

Incubation in darkness for $6 \mathrm{~h}$ substantially reduced $g \ln B$ expression levels in Nostoc strain 0102 (Fig. 5). However, after $1 \mathrm{~h}$ of reillumination the $g \ln B$ expression had already risen to a higher level than that noted before the dark incubation. Addition of fructose before the onset of the dark incubation prevented these effects to a large extent (Fig. 5).
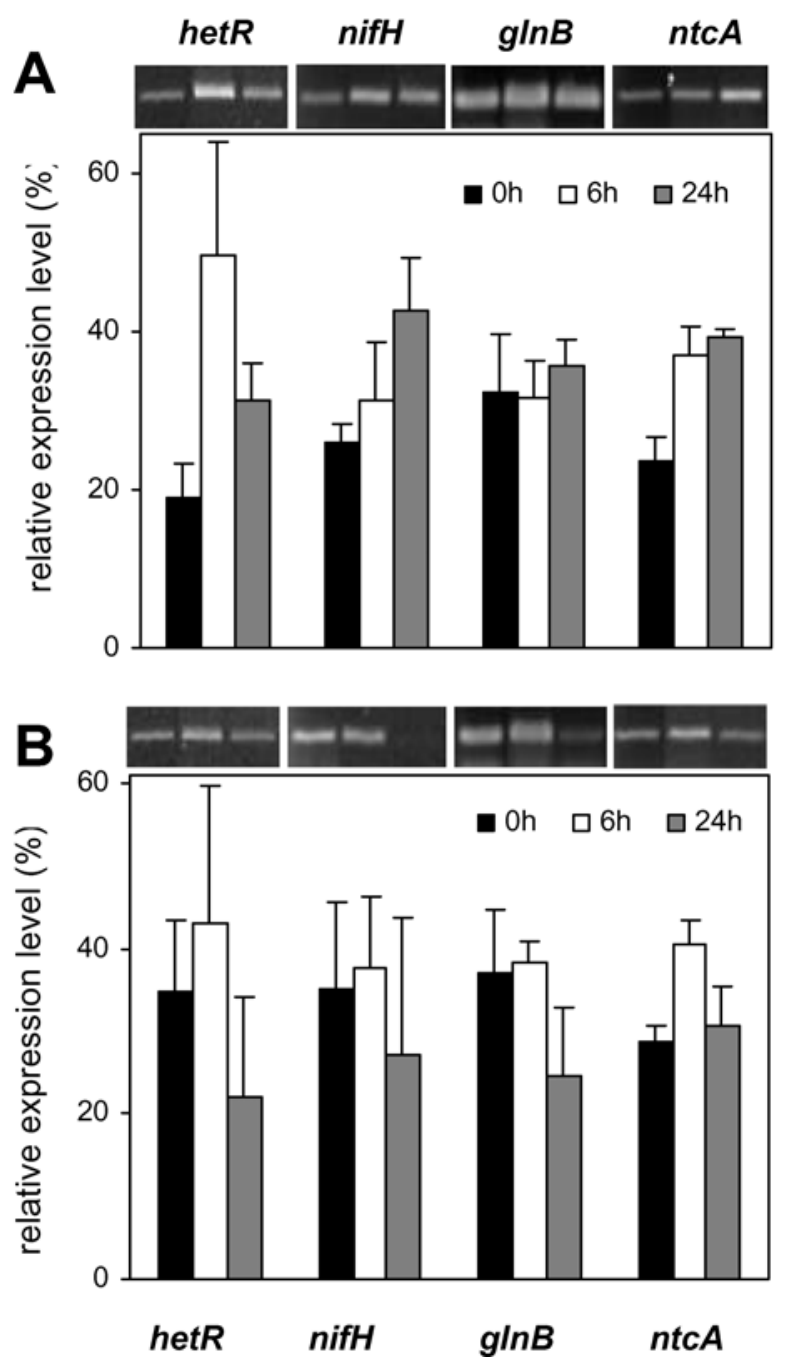

Fig. 4. Transcription profiles of hetR, nifH, $g \ln B$, and $n t c A$ in free-living Nostoc strain 0102 isolated from Gunnera symbiosis. Gels show reverse transcription-polymerase chain reactions from a single experiment, and the histograms show the average relative band intensity from three separate experiments. The total expression level from three samples was set as $100 \%$. Samples were isolated at 0,6 , and $24 \mathrm{~h}$ after adding A, 5 $\mathrm{mM}$ fructose or $\mathbf{B}, 30 \mu \mathrm{M}$ MSX (L-methionine-D,L-sulfoximine). Values are the mean \pm standard error $(n=3)$.

\section{DISCUSSION}

Immediately after entering Gunnera gland cells as nonheterocystous motile hormogonia (infection units), Nostoc filaments redifferentiate into a vegetative multiheterocystous phenotype, radically different from that of its free-living state (Bergman 2002; Johansson and Bergman 1992; Rai et al. 2000; Söderbäck et al. 1990). Simultaneously as the plant grows, a symbiotic age gradient is formed, ranging from the newly infected apex to older mature plant parts of the stems or stolons. Here, we demonstrate for the first time that the genes encountered, hetR, nifH, $n t c A$, and $g \ln B$, are all expressed in planta, and we provide the first cyanobacterial gene expression profiles along such an intact developmental symbiotic gradient. The changes found in expression levels along the profile suggest different regulatory events in symbiosis compared with free-living cyanobacteria. The data also demonstrate that the products of the genes examined are translated into the corresponding proteins (except for HetR, for which no antibody was available) in the intact symbiosis. As similar gene expression patterns were detected in two Gunnera species, the small stoloniferous $G$. magellanica and the large rhizomatous G. manicata, differing in their macromorphology, our findings may be of a more general significance.

Not unexpectedly, a tight relationship between hetR expression and heterocyst frequencies was found, both increasing rapidly in newly infected (younger) parts of the Gunnera stems. In free-living cyanobacteria, het $R$ plays a master role in the regulation of heterocyst development (Adams and Duggan 1999; Buikema and Haselkorn 2001; Meeks and Elhai 2002), and expression of het $R$ is apparent a few hours after removing combined nitrogen from the growth medium (Buikema and Haselkorn 2001; Zhou et al. 1998b). In the symbiosis, the hetR expression continues to increase after section 1 (Fig. 2), where the heterocyst frequency is already at 10 to $20 \%$, indicating that het $R$ in the symbiosis is overexpressed. In free-living cyanobacteria, growth in the absence of combined nitrogen only elicits 5 to $10 \%$ heterocysts (Adams and Duggan 1999). The multiheterocyst phenotype observed in Nostoc strains associated with Gunnera spp. has only been seen in free-living

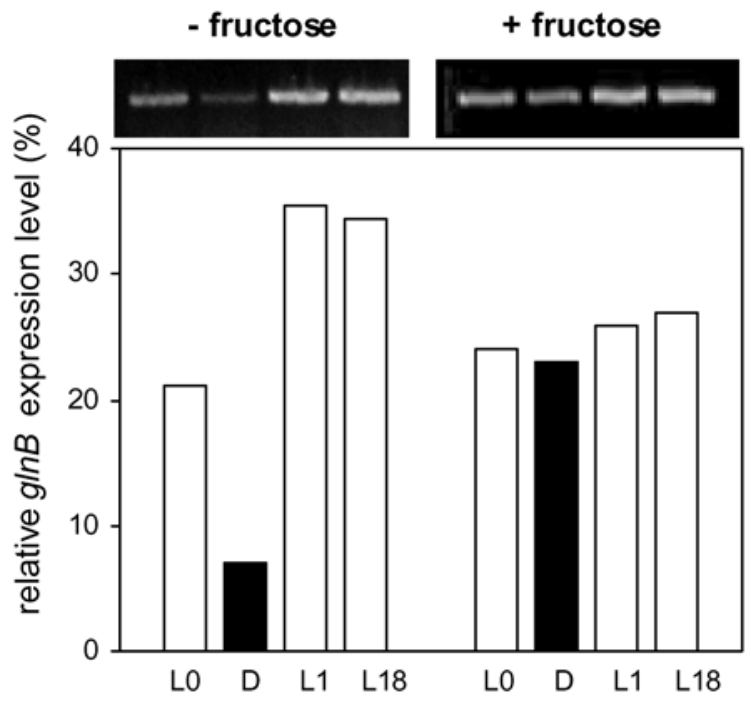

Fig. 5. The effect of darkness on the mRNA levels of $g \ln B$ in a free-living culture of Nostoc strain 0102 isolated from the Gunnera symbiosis. Samples were taken at time 0 (L0), after $6 \mathrm{~h}$ of darkness (D), and 1 (L1) and $18 \mathrm{~h}$ (L18) after again exposing the culture to light. Gels show reverse transcription-polymerase chain reactions from a single experiment, and the histograms show the average relative band intensity from three separate experiments. 
cyanobacteria after introducing extra copies of hetR (Buikema and Haselkorn 1991) or in a patS mutant in which PatS no longer can laterally inhibit adjacent vegetative cells from becoming heterocysts (Yoon and Golden 1998). It is therefore possible that the plant controls the expression of one or both of these genes, but as het $R$ is overexpressed, we suggest that this gene is the primary target.

In parallel with hetR, expression of the transcription factor $n t c A$ was enhanced along the younger parts of the Gunnera developmental profile. ntcA transcription levels were also raised when inhibiting ammonia assimilation (adding MSX) in the Gunnera isolate Nostoc 0102, although moderately. NtcA both triggers heterocyst development (Wei et al. 1994) and is necessary for heterocyst function (Frias et al. 1994). The tight correlation between $n t c A$ and hetR detected here indicates that the mutual dependence found between these genes in free-living cyanobacteria (Muro-Pastor et al. 2002) also prevails in symbiosis. The fact that the expression of hetR was up-regulated before $n t c A$, both in symbiosis and in the isolate Nostoc 0102 (Figs. 2A and $\mathrm{C}$ and 4A) is also in accordance with these findings. We therefore propose that the plant indirectly governs het $R$ expression (and heterocyst frequencies) by controlling either $n t c A$ expression, action, or both.

In both Synechococcus strain WH 7803 and Anabena strain PCC 7120, the expression of ntcA is up-regulated in response to lowered nitrogen levels (Lindell et al. 1998; Muro-Pastor et al. 2002). Considering the modest upshift of ntcA and the lack of any significant upshift of hetR in the free-living isolate Nostoc 0102 on addition of MSX (Fig. 4A and B) but the clear upshifts of the same genes in younger parts of the Gunnera stem, a more severe $\mathrm{N}$ starvation is likely to be experienced in Nostoc isolates in symbiosis. Indeed, most of the dinitrogen fixed by the cyanobiont is released and assimilated by the host plant (Silvester and Smith 1969; Silvester et al. 1996). Besides being nitrogen-starved, the cyanobiont is supplied with fixed carbon from the plant (Black et al. 2002; Söderbäck and Bergman 1993), which may further enhance $\mathrm{C}: \mathrm{N}$ ratios and thereby $n t c A$ expression. This is supported by increased $n t c A$ transcript levels on addition of fructose to cultures of Nostoc strain 0102 (Fig 4A). High $\mathrm{C}: \mathrm{N}$ ratios are possibly also involved in the enhanced het $R$ expression in cyanobionts of young plant tissues, as fructose stimulated hetR expression in Nostoc strain 0102 (Fig. 4A) and as het $R$ is not expressed in darkness unless a source of fixed carbon is made available (Wouters et al. 2000). The decreasing transcript levels detected after section 6 for both $n t c A$ and hetR may be due to death and degradation of the cyanobiont. It has been shown that the supply of carbon is directed almost exclusively towards younger symbiotic tissues in G. magellanica (Söderbäck and Bergman 1993).

As the $g \ln B$ expression was inversely correlated with $n t c A$ expression along the symbiotic profile, the expression in cyanobionts may not be governed by NtcA as in unicellular cyanobacteria (Hisbergues et al. 1999; Lee et al. 1999). In the latter, the $\mathrm{P}_{\text {II }}$ protein (encoded by $g \ln B$ ) regulates both inorganic carbon and nitrate uptake and is modified by a redox signal. Here, we show that a lowered nitrogen status (MSX treatment) or enhanced carbon status (fructose enrichment) $(>\mathrm{C}: \mathrm{N}$ ratio) did not significantly alter $g \ln B$ expression in the free-living Nostoc strain 0102. However, as in unicellular cyanobacteria (GarciaDominguez and Florencio 1997), darkness dramatically downregulated $g \ln B$ expression and addition of fructose circumvented this effect (Fig. 5). Indeed, Nostoc isolates in association with Gunnera spp. end up in darkness and are simultaneously supplied with plant photosynthate (C) (Black et al. 2002; Söderbäck and Bergman 1993). In addition, the upregulation of $n t c A$ and hetR, also suggest enhanced $\mathrm{C}: \mathrm{N}$ ratios in younger parts as discussed above. The anomalous $g \ln B$ expression pattern in Nostoc isolates along the Gunnera spp. profile may therefore be connected to a not-yet-defined regulatory function of $g \ln B$ in heterocystous cyanobacteria, or the host plant may circumvent normal controls of $g \ln B$ expression, e.g., by uncoupling its expression from NtcA. It is also possible that the transformation of most of the vegetative cells into heterocysts, the latter with high expression levels of hetR and nifH and possibly also of $n t c A$ but with unknown $g \ln B$ expression levels, may also be involved in the overall differences in gene expression discovered along the Gunnera developmental profile.

As nitrogenase is only synthesized in heterocysts in $G$. magellanica (Söderbäck et al. 1990), the positive correlation between NifH levels, hetR expression, and heterocyst frequencies was expected. Addition of fructose to the free-living Nostoc strain 0102 also increased nifH levels but not until after $24 \mathrm{~h}$, the approximate time it takes for heterocysts to develop. The differences observed in nifH transcription and NifH appearance along the developing gradient may be due to altered rates of nitrogenase synthesis and turnover in symbiosis. For instance, nitrogenase is well preserved even in the oldest parts of the Gunnera developmental profile, i.e., long after nitrogenase activity is lost (Söderbäck et al. 1990).

Taken together, our data show that the cyanobacterial genes, $h e t R$, nifH, $n t c A$, and $g \ln B$ selected for being involved in key regulatory processes, were all expressed in Nostoc isolates residing intracellularly in Gunnera cells, as were the corresponding gene products examined. In addition, the genes showed distinct expression profiles related to the developmental profile of the host, suggesting that the plant has an important regulatory role. The overexpression of $n t c A$ and hetR and the contrasting downregulation of $g \ln B$ (and $g \ln A$ [Söderbäck 1992]) are features indicating important regulatory differences between symbiotic and free-living cyanobacteria. The apparent great potential held by plants to genetically manipulate symbiotic prokaryotes for their own benefit may explain why cyanobacteria once became fully integrated and turned into chloroplasts.

\section{MATERIALS AND METHODS}

\section{Organisms and growth conditions.}

Specimens of Gunnera magellanica Lam., a relatively small species indigenous to South America (Osborne 2002), and Gunnera manicata, a relatively large species, were grown in the Department of Botany greenhouse at Stockholm University, Stockholm, Sweden.

Glands were cut from the Gunnera stems with a scalpel in a sterile hood, were washed with $70 \%$ ethanol and sterile water,

Table 1. Primers used for reverse-transcription-polymerase chain reaction ${ }^{\mathrm{a}}$

\begin{tabular}{llll}
\hline Target & Conditions & \multicolumn{1}{c}{ Forward primer sequence (5' to 3') } & Reverse primer sequence (5' to 3') \\
\hline$g \ln B$ & Standard & GGGGWTGAARRTWGARGC KATTAT & GGGGAARATYTTRCCRTCRCCRATTTC \\
$h e t R$ & Standard & GGCGKWATATGAGTA & CGCCCRCCWWCTTGG \\
$n i f H$ & Standard & AGACAGATAGCTTTCTACGGT & KTCTGGTGCGTACTCGTTAAC \\
ntcA & cyc: 45 & ACAGGTTTATGCACRGTAATC & GCGATCCTGCCGAACGA \\
$16 \mathrm{~S}$ rRNA & ann:70; cyc:15 & TGTAAACGACGGCCAGTCCAGACTCCTACGGGAGGCAGC & CGCGTTAGCTACGGCACGGCTCGG \\
\hline
\end{tabular}

${ }^{a} \mathrm{~W}=\mathrm{T}, \mathrm{R}=\mathrm{AG}, \mathrm{K}=\mathrm{GT}, \mathrm{Y}=\mathrm{CT}$. cyc indicates the number of cycles. ann indicates annealing temperature. 
and were placed on a BG $11_{0}(1.5 \%$ agar) plate (Stanier et al. 1971). The plate was incubated under continuous light for about a month, during which hormogonia developed out from the gland. The hormogonia were transferred to liquid BG $11_{0}$ medium and were grown under continuous light as described previously (Johansson and Bergman 1992). This isolate, Nostoc 0102, was used for experiments on free-living Nostoc. Aliquots (2-ml) from the culture were centrifuged (at 12,000 $\mathrm{rpm}$ for $5 \mathrm{~min}$ ), and the cell pellet was frozen at $-80^{\circ} \mathrm{C}$.

\section{Isolation of cyanobiont cells void of contaminating plant materials.}

Glands were excised from different positions along the stem under a light microscope and were placed in 1.5- $\mathrm{ml}$ tubes containing $0.1 \mathrm{ml}$ of buffer A (200 $\mathrm{ng}$ of bovine serum albumin per $\mu \mathrm{l}, 1 \%$ Tween $20,15 \mathrm{mM} \mathrm{MgCl} 2,2 \%$ polyvinylpyrrolidone [PVP]). The glands were homogenized with a plastic pestle, and the cyanobiont filaments were photographed under a light microscope. The homogenized glands were then washed three times with buffer A and further homogenized in Buffer B (1\% Tween 20, $15 \mathrm{mM} \mathrm{MgCl}_{2}, 2 \%$ PVP) until the cyanobiont became single cells. These cells were washed three times with Buffer B and three times with sterile water. The pellets were separated into two tubes and were frozen at $-80^{\circ} \mathrm{C}$ for later Western blot and RT-PCR analysis.

\section{RNA isolation.}

To isolate RNA, the frozen cyanobacterial cells were placed in liquid nitrogen and were ground immediately with a plastic pestle. RLT buffer provided with the RNeasy Plant mini Kit (Qiagen, GmbH, Hilden, Germany) $(0.45 \mathrm{ml})$ was added to the tube before the samples were thawed. Further steps followed the protocol provided with the kit. Final elution of RNA was performed with $30 \mu \mathrm{l}$ of water. This method typically resulted in up to $100 \mu \mathrm{g}$ of high quality RNA. Quantity and quality controls of RNA preparations included UV spectrophotometry and gel electrophoresis (data not shown). To remove any possible contaminating DNA from RNA preparations, a DNA-free kit (Ambion, Austin, TX, U.S.A.) was used. This kit is designed to remove contaminating DNA to levels below the limit of detection by routine PCR.

\section{Primer design for RT-PCR.}

Primer sequences and conditions used for RT-PCR are detailed in Table 1 . The primers were supplied by DNA Technology A/S (Aarhus, Denmark).

\section{RT-PCR.}

RT-PCR was performed using the Titan one-tube RT-PCR system (Roche GmbH, Mannheim, Germany) and a Perkin Elmer GeneAmp 2400 Thermocycler (Wellesley, MA, U.S.A.). The Titan one-tube RT-PCR kit is a one step, one tube system in which first-strand cDNA synthesis relies on one of the gene-specific primers used for the amplification step. cDNA synthesis and PCR are coupled to a continuous procedure in which all components are included in a single tube. The reaction volume was scaled down to a final total of $25 \mu \mathrm{l}$. A single standard reaction included $100 \mathrm{ng}$ of total RNA. cDNA synthesis was performed at $50^{\circ} \mathrm{C}$ for $30 \mathrm{~min}$, followed by a single step at $94^{\circ} \mathrm{C}$ for 3 min and 10 cycles using the PCR protocol: $94^{\circ} \mathrm{C}$ for $30 \mathrm{~s}, 55^{\circ} \mathrm{C}$ for $45 \mathrm{~s}$, and $68^{\circ} \mathrm{C}$ for $30 \mathrm{~s}$. This was immediately followed by 30 cycles of the subsequent protocol: $94^{\circ} \mathrm{C}$ for $30 \mathrm{~s}, 55^{\circ} \mathrm{C}$ for $60 \mathrm{~s}$, and $72^{\circ} \mathrm{C}$ for $30 \mathrm{~s}$, plus five additional seconds per cycle. The reactions were cooled to $4^{\circ} \mathrm{C}$ after a final extension at $72^{\circ} \mathrm{C}$ for $10 \mathrm{~min}$. In instances in which these standard conditions did not produce satisfactory results, programming was adjusted as indicated in Table 1.
Reactions $(10 \mu \mathrm{l})$ were loaded onto $1.5 \%$ agarose gels for analysis. After electrophoresis for $30 \mathrm{~min}$ at $100 \mathrm{~V}$, the gels were stained with ethidium bromide $(1 \mu \mathrm{g} / \mathrm{ml})$ and were digitally recorded. All assays were performed at least three times. The quantification of the images was performed using the ImageQuant software from Amersham Biosciences (Uppsala, Sweden). To detect putative DNA contamination of the RNA samples, negative controls were run without the RT reaction.

\section{Preparation of protein extracts.}

For protein extraction, a few grains of acid-washed sand (sea sand, particle size 0.1 to $0.3 \mathrm{~mm}$; Merck, Darmstadt, Germany) were added to each cyanobacterial pellet (approximately 25 $\mathrm{mg}$ fresh weight), followed by grinding in liquid nitrogen with a plastic pestle in 1.5-ml tubes. Sample buffer (125 $\mu \mathrm{l} ; 2 \%$ sodium dodecyl sulfate (SDS) (wt/vol), 2.5\% 2-mercaptoethanol (vol/vol), 10\% glycerol (vol/vol), 25 mM Tris-HCl, pH 6.8) containing a protease inhibitor cocktail (Complete; Boehringer $\mathrm{GmbH}$, Ingelheim, Germany) was added according to the manufacturer's instructions. The samples were boiled for 5 min, and the lysates were cleared of cell debris by centrifugation for $10 \mathrm{~min}$ at $15,800 \times \mathrm{g}$. In order to estimate the relative protein concentration in the samples, aliquots of the protein extracts were taken and were analyzed using the BCA protein assay kit (Pierce Biotechnology, Inc., Rockford, IL, U.S.A).

\section{Immunoblotting procedures.}

Equal amounts of proteins were loaded into each well of $10 \%$ SDS-polyacrylamide gel electrophoresis gels, which were electrophoresed at a constant current of $20 \mathrm{~mA}$ per gel. Duplicate gels were electrophoresed in parallel, and one was stained with Coomassie R250, while the other was further processed for Western blot analysis. Proteins were transferred by wet blotting onto a polyvinylidene diflouride membrane (Hybond-P; Amersham Biosciences) for $1.5 \mathrm{~h}$ at $30 \mathrm{~V}$. The buffer tank (mini trans-blot transfer cell; BioRad, Hercules, CA, U.S.A.) was filled with transfer buffer (25 mM Tris base, $19.2 \mathrm{mM}$ glycine, $20 \%$ methanol, and $0.05 \% \mathrm{SDS}$ (wt/vol), $\mathrm{pH}$ 8.3). Blotted membranes were blocked for $1 \mathrm{~h}$ in $5 \%$ skimmed milk (wt/vol) in TTBS (20 mM Tris base, $0.8 \% \mathrm{NaCl}$ [wt/vol], $\mathrm{pH} 7.6$, and $0.1 \%$ Tween 20 [vol/vol]) followed by two 2-min washes in TTBS. The membranes were incubated in the primary antibody $1 \mathrm{~h}$ at room temperature. The primary antibodies used were rabbit anti-Rhodospirillum rubrum nitrogenase (Fe protein) at a 1:10,000 dilution, anti-Anabena strain PCC $7120 \mathrm{NtcA}$ at a 1:2,000 dilution, and anti-Synechococcus strain PCC $7942 \mathrm{P}_{\text {II }}$ protein (gift of K. Forchhammer, University of Copenhagen, Denmark) at a 1:5,000 dilution. After washing three times for $15 \mathrm{~min}$ each in TTBS, the membranes were incubated for $1 \mathrm{~h}$ in secondary antibody at a 1:8,000 dilution in TTBS (affinity-purified polyclonal goat anti-rabbit/HRP antibodies; Amersham Biosciences). After washing three times for 15 min each in TTBS, detection was performed using the ECL plus system (Amersham Biosciences) according to the manufacturer's instructions.

\section{ACKNOWLEDGMENTS}

The financial support from The Swedish Research Council, the WennerGren Foundation, and the CYANOFIX program of the European Science Foundation is gratefully acknowledged.

\section{LITERATURE CITED}

Adams, D. G., and Duggan, P. S. 1999. Heterocyst and akinete differentiation in cyanobacteria. New Phytol. 144:3-33.

Bergman, B., Johansson, C., and Söderbäck E. 1992a. The Nostoc-Gunnera symbiosis. New Phytol. 122:379-400. 
Bergman, B., Rai, A. N., Johansson, C., and Söderbäck, E. 1992b. Cyanobacterial-plant symbiosis. Symbiosis 14:61-81.

Bergman, B. 2002. Gunnera-Nostoc symbiosis. Pages 207-232 in: Cyanobacteria in Symbiosis. A. N. Rai, B. Bergman, and U. Rasmussen, eds. Kluwer Academic Publishers, Dordrecht, The Netherlands.

Bergman, B., Matveyev, A., and Rasmussen, U. 1996. Chemical signaling in cyanobacterial-plant symbiosis. Trends Plant Sci. 1:191-197.

Black, K. G., Parsons, R., and Osborne, B. A. 2002. Uptake and metabolism of glucose in the Nostoc-Gunnera symbiosis. New Phytol. 153:297-305

Buikema, W. J., and Haselkorn, R. 1991. Characterization of a gene controlling heterocyst differentiation in the cyanobacterium Anabaena 7120. Genes Dev. 5:321-330.

Buikema, W. J., and Haselkorn, R. 2001. Expression of the Anabaena $h e t R$ gene from a copper-regulated promoter leads to heterocyst differentiation under repressing conditions. Proc. Natl. Acad. Sci. U.S.A. 98:2729-2734.

Frias, J. E., Flores, E., and Herrero, A. 1994. Requirement of the regulatory protein NtcA for the expression of nitrogen assimilation and heterocyst development genes in the cyanobacterium Anabaena sp. PCC 7120. Mol. Microbiol. 14:823-832.

Garcia-Dominguez, M., and Florencio, F. J. 1997. Nitrogen availability and electron transport control the expression of $g \ln B$ gene (encoding $\mathrm{P}_{\mathrm{II}}$ protein) in the cyanobacterium Synechocystis sp. PCC 6803. Plant Mol. Biol. 35:723-734.

Hanson, T. E., Forchhammer, K., Tandeau de Marsac, N., and Meeks, J. C. 1998. Characterization of the $g \ln B$ gene product of Nostoc punctiforme strain ATCC 29133: $g \ln B$ or the $\mathrm{P}_{\mathrm{II}}$ protein may be essential. Microbiol. 144:1537-1547.

Herrero, A., Muro-Pastor, A. M., and Flores, E. 2001. Nitrogen control in cyanobacteria. J. Bacteriol. 183:411-425.

Hisbergues, M., Jeanjean, R., Joset, F., Tandeau de Marsac, N., and Bedu, S. 1999. Protein $\mathrm{P}_{\mathrm{II}}$ regulates both inorganic carbon and nitrate uptake and is modified by a redox signal in Synechocystis PCC 6803. FEBS (Fed. Eur. Biochem. Soc.) Lett. 463:216-220.

Irmler, A., Sanner, S., Dierks, H., and Forchhammer, K. 1997. Dephosphorylation of the phosphoprotein P (II) in Synechococcus PCC 7942 : Identification of an ATP and 2-oxoglutarate-regulated phosphatase activity. Mol. Microbiol. 26:81-90.

Johansson, C., and Bergman, B. 1992. Early events during the establishment of Gunnera/Nostoc symbiosis. Planta 188:403-413

Lee, H. M., Vazquez-Bermudez, M. F., and Tandeau de Marsac, N. 1999. The global nitrogen regulator NtcA regulates transcription of the signal transducer $\mathrm{P}_{\mathrm{II}}(\mathrm{G} \ln \mathrm{B})$ and influences its phosphorylation level in response to nitrogen and carbon supplies in the cyanobacterium Synechococcus sp. strain PCC 7942. J. Bacteriol.181:2697-2702.

Leganes, F., Fernandez-Pinas, F., and Wolk, C. P. 1994. Two mutations that block heterocyst differentiation have different effects on akinete differentiation in Nostoc ellipsosporum. Mol. Microbiol.12:679-684

Lindell, D., Padan, E., and Post, A. F. 1998. Regulation of $n t c A$ expression and nitrite uptake in the marine Synechococcus sp. strain WH 7803. J. Bacteriol. 180:1878-1886.

Luque, I., Flores, E., and Herrero, A.1994. Molecular mechanism for the operation of nitrogen control in cyanobacteria. EMBO (Eur. Mol. Biol. Organ.) J. 13:5794.

Martin W., Rujan T., Richly E., Hansen A., Cornelsen S., Lins T., Leister D., Stoebe B., Hasegawa M., and Penny D. 2002. Evolutionary analysis of Arabidopsis, cyanobacterial, and chloroplast genomes reveals plastid phylogeny and thousands of cyanobacterial genes in the nucleus. Proc. Natl. Acad. Sci. U.S.A. 99:12246-12251.

Meeks, J. C., and Elhai, J. 2002. Regulation of cellular differentiation in filamentous cyanobacteria in free-living and plant-associated symbiotic growth states. Microbiol. Mol. Biol. Rev. 66:94-121.

Muro-Pastor, M. I., Reyes, J. C., and Florencio, F. J. 2001. Cyanobacteria perceive nitrogen status by sensing intracellular 2-oxoglutarate levels. J. Biol. Chem. 276:38320-38328.
Muro-Pastor, A. M., Valladares, A., Flores, E., and Herrero, A. 2002. Mutual dependence of the expression of the cell differentiation regulatory protein HetR and the global nitrogen regulator NtcA during heterocyst development. Mol. Microbiol. 44:1377-1385.

Nilsson M., Bergman, B., Rasmussen, U. 2000. Cyanobacterial diversity in geographically related and distant host plants of the genus Gunnera. Arch. Microbiol. 173:97-102.

Osborne, B. A., Sprent, J. I. 2002. Ecology of Nostoc-Gunnera symbiosis. Pages 207-232 in: Cyanobacteria in Symbiosis. A. N. Rai, B. Bergman, and U. Rasmussen, eds. Kluwer Academic Publishers, Dordrecht, The Netherlands.

Rai, A. N., Söderbäck, E., and Bergman, B. 2000. Cyanobacterium-plant symbioses. New Phytol. 147:449-481.

Ramasubramanian, T. S., Wei, T. F., Oldham, A. K., and Golden, J. W. 1996. Transcription of the Anabaena sp. strain PCC 7120 ntcA gene: Multiple transcripts and NtcA binding. J. Bacteriol. 178:922-926.

Rasmussen, U., Svenning, M. M. 2001. Characterization by genotypic methods of symbiotic Nostoc strains isolated from five species of Gunnera. Arch. Microbiol. 176:204-210.

Rogerson, A. C. 1979. Modifiers of heterocyst repression and spacing and formation of heterocysts without nitrogenase in the cyanobacterium Anabaena variabilis. J. Bacteriol. 140:213-219.

Schopf, J.W. 2000. The fossil record: Tracing the roots of the cyanobacterial lineage. Pages 13-35 in: The Ecology of Cyanobacteria. B. A Whitton and M. Potts, eds. Kluwer Academic Publishers, Dordrecht, The Netherlands,

Silvester, W. B., and Smith, D. R. 1969. Nitrogen fixation by GunneraNostoc symbiosis. Nature 224:1231.

Silvester, W. B., Parsons, R., and Watt, P. W. 1996. Direct measurement of release and assimilation of ammonia in the Gunnera-Nostoc symbiosis. New Phytol. 132:617-625.

Stanier, R. Y., Kunisawa, R., Mandel, M., and Cohen-Bazire G. 1971. Purification and properties of unicellular blue-green algae (order Chroococcales). Bacteriol. 35:171-205.

Stewart, W. D. P., and Rowell, P. 1975. Effects of L-methionine-DLsulphoximine on the assimilation of newly fixed $\mathrm{NH}_{3}$, acetylene reduction and heterocyst production in Anabaena cylindrica. Biochem. Biophys. Res. Commun. 65:846-856.

Söderbäck, E. 1992. Developmental patterns in the Nostoc-Gunnera symbiosis. Doctoral thesis. Stockholm University, Stockholm, Sweden.

Söderbäck, E., and Bergman, B. 1993. The Nostoc-Gunnera symbiosis: Carbon fixation and translocation. Physiol. Plant. 89:125-132.

Söderbäck, E., Lindblad, P., and Bergman, B. 1990. Developmental patterns related to nitrogen fixation in the Nostoc-Gunnera magellanica Lam. symbiosis. Planta 182:355-362.

Tanigawa, R., Shirokane, M., Maeda, S. S., Omata, T., Tanaka, K., and Takahashi, H. 2002. Transcriptional activation of NtcA-dependent promoters of Synechococcus sp. PCC 7942 by 2-oxoglutarate in vitro. Proc. Natl. Acad. Sci. U.S.A. 99:4251-4255

Vazquez-Bermudez, M. F., Herrero, A., and Flores, E. 2002. 2-oxoglutarate increases the binding affinity of the NtcA (nitrogen control) transcription factor for the Synechococcus glnA promoter. FEBS (Fed. Eur. Biochem. Soc.) Lett. 512:71-74.

Wei, T.-F., Ramasubramanian, T. S., and Golden, J. W. 1994. Anabena sp. strain PCC 7120 ntcA gene required for growth on nitrate and heterocyst development. J. Bacteriol. 176:4473-4482.

Wouters, J., Janson, S. P., and Bergman, B. 2000. The effect of exogenous carbohydrates on nitrogen fixation and hetR expression in Nostoc PCC 9229 forming symbiosis with Gunnera. Symbiosis 28:63-76.

Yoon, H.-S., and Golden, J. W. 1998. Heterocyst pattern formation controlled by a diffusible peptide. Science 282:935-938.

Zhou, R., Wei, X., Jiang, N., Li, H., Dong, Y., His, K. L., and Zhao, J. 1998a. Evidence that HetR protein is an unusual serine-type protease. Proc. Natl. Acad. Sci. U.S.A. 95:4959-4963

Zhou, R., Cao, Z., and Zhao, J. 1998b. Characterization of HetR protein turnover in Anabaena sp. PCC 7120. Arch. Microbiol. 169:417-423. 